
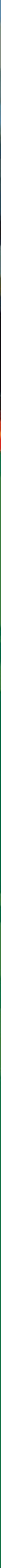


\section{1 \\ Living with bushfire: What do people expect?}

\section{Sally Bushnell and Alison Cottrell}

The physical and economic impact of bushfires has been well documented, particularly in the United States of America. A National Interagency Fire Centre (NIFC, 2003) report revealed that in 2002, more than 88,450 recorded fires burned 6.9 million acres and 2,381 structures, and the total suppression cost for the federal agencies reached \$US1.6 billion. Figures for preceding years are similar, but suggest that these impacts from bushfire are growing in magnitude. Similar bushfire impacts have been recorded in Australia. The Ash Wednesday bushfires of 16 January 1983 are perhaps the most renowned in Australian history, and the following statistics suggest why: in Victoria and South Australia 76 people died; 2,463 houses were destroyed; and 360,00o hectares of land was burned (Ramsay \& Rudolph, 2003), total property loss were estimated to be over $\$ A 400$ million (Willis, 2004). The January 2003 bushfires, in New South Wales, Victoria and South Australia, rivalled Ash Wednesday in terms of widespread destruction and property loss (Gilbert, 2004), where four lives were lost, over 500 homes destroyed and total damage cost more than $\$ \mathrm{~A} 300$ million (Willis, 2004). The 2003 fires were also a harsh reminder of how susceptible Australia is to bushfire. In a global context, Australia is widely regarded as the most fireprone country (Rohrmann, 1999; Gilbert, 2004). Furthermore, the situation may be worsening due to long-term droughts and higher average temperatures (Whittaker \& Mercer, 2004).

Loss of life and property, and the economic costs associated with suppressing fires and recovering from fire, are significant and obvious outcomes of bushfire, however there are many other impacts and costs of bushfire which are often not anticipated because they are more indirect and therefore not as obvious to the general public. These include social and economic costs to the individual, family and community such as the loss of livelihoods, interruption of life patterns and relationships, and in some cases the entire social fabric that defines a population as a community can be severely weakened (David, Baish \& Hearn Morrow, 1999).

Because fire is, in general terms, a natural ecosystem process (Beringer, 2000), it is a hazard or a disaster only when human life and property become 
threatened or destroyed; "The disaster itself occurs within society and not within nature" (Weichselgartner, 2001: 86). Indeed, in many areas of Australia and the world that have evolved with fire, bushfire plays a positive and sometimes crucial role for native vegetation and animals, which depend on fire for regeneration, refuge, protection and reproduction (Beringer, 2000; Haswell \& Brown, 2002). Accordingly, the climate, vegetation type and existence of ignition sources characteristic of these areas are compatible with fire and thus indicate that fire is inevitable (McGee \& Russell, 2003).

In many countries, including Australia, there is a growing pattern of population movement into peri-urban areas (Hugo, 2002). These areas tend to be bushfire prone and because of the resultant, ever-increasing mix of people, property and bushfire (leading to the potential consequences of physical, economic and social impacts described above) bushfire is now a significant hazard (McCaffrey, 2004).

\section{The peri-urban area and bushfire risk}

Cottrell (2005) summarised a number of terms used to describe the periurban area, these include the wildland-urban interface, rural-urban fringe and exurban, for example. The peri-urban area includes the extension of urban areas into rural areas and regional urban areas. There are many types (see Cottrell, 2005), however all peri-urban areas are typically areas where structures (whether residential, industrial, recreational, or agricultural) are located adjacent to or among combustible wildland fuel (CFS, 2004). There are many reasons why people are moving into peri-urban areas, a commonly cited reason is the attraction to rural areas because of the associated aesthetics of the landscape; other reasons include cheaper house prices and reduced crime, pollution and crowding (Monroe, Bowers \& Hermansen, 2003a). In essence these are quality of life issues.

However, with the potential benefits of living in the peri-urban area come potential costs. The peri-urban area is the most fire vulnerable due to mixture of bushland, houses, people, paddocks and stock (Haswell \& Brown, 2002). The fire risk exposure has indeed grown significantly over the last several decades (McKee, Berrens, Jones, Helton \& Talberth, 2004) and is expected to increase as peri-urban populations grow (Gardner, Cortner \& Widaman, 1987). Furthermore, it has become quite clear that many bushfires cannot be fully controlled resulting in serious economic, social and ecological damage, as demonstrated by the previously mentioned statistics. Therefore, people living in peri-urban areas are exposed to a significant level of risk from bushfire and its consequences. 


\section{Reducing the risk}

Traditionally risk reduction strategies have been the responsibility of the government and its agencies, and have included fire suppression, fire prevention through reducing fuel loads and building firebreaks, building codes and zoning (the latter two however have not been implemented to such an extent, and not necessarily with other strategies, to significantly reduce the bushfire risk). More recently there has been a redistribution of rights and obligations and/or changes in the allocation of costs and benefits from the government to the public (Winter \& Fried, 2000). For example, educational messages are commonly disseminated to the public to encourage individual fire prevention efforts (e.g., create a defensible space around the home by clearing vegetation), ordinances have been imposed requiring individuals to fireproof their homes (e.g., retrofitting roofs) or to pay tax on additional fire protection, and homeowners are often motivated themselves to take preventative measures voluntarily and/or engage in community programs to reduce the fire risk to themselves and their neighbourhood (Winter \& Fried, 2000; McKee, Berrens, Jones \& Talberth, 2004).

Given that bushfires are often uncontrollable and fire-fighting and other emergency services and resources become so overwhelmed that it is impossible to provide people and property with adequate protection, people need to take some responsibility to protect themselves and their property. However, there is considerable empirical evidence that households in areas prone to natural hazards risk under-invest in protective measures (McKee et al., 2004). Government intervention has often been unsuccessful due to lack of enforcement of ordinances, lack of support from the public or opposition to fire prevention strategies, and the public have often been unmotivated to take action themselves due to a lack of incentives or a lack of understanding of the risk (Winter \& Fried, 2000; McKee et al., 2004).

There are no guides to 'best practise' for community safety, not one strategy or combination of strategies are necessarily successful, nor have been adequately successful as discussed above. Therefore bushfire in the periurban areas has become a major, often contentious, issue, and mitigating the risk and reducing the impact of bushfire is a problematic and complex challenge, but one that requires urgent attention. In addressing the challenge, input from the community at risk is important, if not crucial. Policies and management strategies should reflect what people expect or at least will accept. But what do people expect? Intuitively, people do not want to lose their lives or house to bushfire or suffer any other consequences of bushfire, but do they perceive the risk? Do they actually expect a significant impact? And in terms of protection and resilience, what do they expect of themselves? What do they expect of the fire service? What do they expect of 
the government? To answer these such questions, this paper will review the literature to gain a better understanding of people's knowledge, perceptions, attitudes and expectations in relation to bushfire.

\section{The peri-urban community}

The term community can have a wide range of meanings. A community is a group that has a number of things in common, which may be defined by location, interests, or function for example. A person can belong to a number of different communities, and there can be a number of different communities within a single location. Furthermore communities are not static with changing membership, ideologies or beliefs, for example (Boughton, 1998; Marsh, 2001; Cottrell, 2005). Defining and typifying communities in a location, and their members, is therefore a complex, if not impossible, task, and this may be especially so in peri-urban areas where there is substantial mixing of rural and urban community characteristics.

There are a number of possible factors influencing the diversity of peri-urban communities. Perhaps the most obvious is the composition of communities. Along with long-term residents, there is an influx of people from urban areas which indicates a high proportion of newcomers with urban rather than rural backgrounds, and due to the attraction of the beauty of the rural landscape, there is also a number of weekend and seasonal residents, and holidaymakers. Therefore, substantial differences both within and between peri-urban areas may be observed in terms of demographics and socioeconomic status, life experiences, knowledge, attitudes, opinions, perceptions and expectations, for example. Furthermore, Jakes et al. (2002) also highlighted differences in social capital, human capital and cultural capital between locations within peri-urban areas. Such differences can have a significant bearing on bushfire management, and community preparedness and resilience, and further highlights the issues for fire policies and services. For example, Brunson and Shindler (2004) argue against the "one-size-fitsall" policies and strategies (about fuels management). They found differences between respondent knowledge and acceptability judgements of wildland fuels management, which was associated with location-specific social and environmental factors as well as individual beliefs

\section{Bushfire awareness and risk perception}

Until recently, bushfire has not been perceived as a significant hazard (McCaffrey, 2004). Perhaps because throughout history (unlike other hazards) fire was depended on for warmth, cooking, and to heat water (De Cicco, 1990), and complete fire suppression was successful until only the last few decades. Today it is clear that bushfire is in fact a significant hazard, and 
growing numbers of people are at risk. Risk however is a complex concept, but Meacham (2004) has provided a broad definition:

[Risk is] the possibility of an unwanted outcome in an uncertain situation, where the possibility of the unwanted outcome is a function of three factors: loss or harm to something that is valued (consequence), the event or hazard that may occasion the loss or harm (scenario), and a judgement about the likelihood that the loss or harm will occur (probability) (p. 204).

Assessing risk involves both judging the likely occurrence of an event and the likely damage that will be incurred, thus risk perception can be extremely subjective, especially in regards to bushfire risk (McCaffrey, 2004). There is evidence that risk is perceived differently by experts and non-experts; "experts" tend to base their perception of risk on statistics, however risk perception for lay people is much more complex. Therefore, in addressing risk issues, it is important to understand the risk perception of those at risk to move beyond a purely statistical approach (Meacham, 2004).

Lupton and Tulloch (2002) conduced interviews with a group of Australians to gain a better understanding of the ways in which a range of risks are understood and dealt with by lay people, and how their risk knowledges are constructed and maintained or transformed. They found that risk was defined differently by different interviewees, but the major discourses centred around "the notion of risk as negative, frightening, involving taking a step into the unknown but also a degree of rational judgement and choice on the part of the individual concerning whether or not to take this step" (Lupton \& Tulloch, 2002, p. 331). The interviewees own position in the life course, their gender, age, sexual identity, class and so on phrased the risks to which people felt they were exposed. Risk was seen as a part of life and also strongly tied to an individual's life situation, which both exposed them to certain risk and influenced the ways in which they viewed phenomena as risks or not. Many described a life course trajectory of risk-taking and riskavoidance involving risk-taking when young, avoiding voluntary risk-taking when responsibilities such as family were important, and some reported increased risk-taking again in later years when responsibilities lessened. Few people avoided risk-taking altogether, in fact many argued for the importance of deliberately taking risks.

In Lupton and Tulloch's (2002) study, bushfire was not perceived as a risk to the interviewees themselves nor as a risk to fellow Australians, which is not surprising given that the study was not limited to any particular type of risk, and interviewees were not necessarily at risk of bushfire. However, it was noted that environmental problems in general were not identified as major 
risks by the majority of interviewees. Although "environmental problems" encompasses a wide range of potential risks, it does include natural hazards such as cyclones and floods, as well as bushfire, the risk to which many Australians are exposed. One possible explanation is that perceived risks (to Australians) were closely tied to current issues receiving extensive media attention and public debate at the time of study. Perhaps if the study were undertaken after the 2003 bushfires, which received plenty of media attention and public debate, bushfires may have been identified by interviewees as a risk facing fellow Australians. However, there is evidence that people, even those directly exposed to the risk, simply underestimate the risk of natural hazards (Cunningham \& Kelly, n.d.).

Gaps between individual and community perception of risk and the objective data on the magnitude, frequency and consequences of the hazard can be influenced by a number of issues. Natural hazards, including bushfire, are relatively infrequent and not part of everyday life for a given individual or community, and are thus easily forgotten. Information on the nature of the hazard may be incomplete or ambiguous. In the absence of information, risk estimates are based on little data. Acknowledging the risk may bring about an uncomfortable psychological state, and coupled with the inherent uncertainty of hazards, individuals may resort to various mental strategies including denying the risk (e.g., "it won't happen to me"), or giving in-place adjustments (e.g., fire suppression) the power of complete rather than partial protection, or reasoning that if an event happened recently it won't occur again in the near future (Cunningham \& Kelly, n.d.; Kumagai, Carroll \& Cohn, 2004a; McCaffrey, 2004). Furthermore, "dread risk", "unknown risk" and number of people exposed have been found to influence the gap in risk perception and actual risk. Bushfire fails to score high in this instance also: in some cases bushfire evokes little dread due to a feeling of control by agencies undertaking suppression of fires. McCaffrey (2004) argues that in Canada the extent of bushfire is reasonably limited and there are few fatalities, particularly in more recent times; bushfire and its effects are wellknown; and few people are exposed due to adequate warning for evacuation. Individual risk perception can also be shaped by the community in which the individual lives. Risk perceptions are filtered by community influences such as shared experience and existing power relationships, and a cohesive community will continually shape and mould their collective perceptions of problems (Flint \& Luloff, 2005). Gough (2000) inferred from her study that community structure and cohesiveness is linked to a better understanding and acceptance of natural hazard risk. 


\section{Vulnerability and Risk}

Vulnerability is inextricably linked with risk. Vulnerability describes the degree of susceptibility to harm of those at risk (Young, 1998). Vulnerability, in terms of natural hazards, is obviously influenced by geography; a person living in a fire-prone area is thus vulnerable to the effects of bushfire. However, how vulnerable a person is can be influenced by socioeconomic characteristics and other characteristics of the individual, knowledge and experience of the hazard, and also the community in which a person lives in terms of social structures, community cohesiveness and support, and the structural environment in terms of infrastructure (Young, 1998; AndersonBerry, 2003). Vulnerability can also be determined by a person's perception of risk; a person who underestimates the level of risk will likely expose themselves to the risk to a greater extent than a person with more realistic perceptions thereby becoming more vulnerable (Anderson-Berry, 2003). Vulnerability however, similarly to risk, is not always perceived realistically. People with adequate threat knowledge and risk perception do not always perceive their own susceptibility to the threat, and furthermore often perceive that, in the event of a hazard, that they would be resilient and recover quickly (Odgers, 2002). For example, when a person has experienced a minor hazard, or even survived a disaster, they may infer from their ability to cope in that instance the ability to cope with any future occurrence of the hazard, or assume that a future occurrence will not exercise an adverse influence on them (normalisation bias). In addition, people often simply rate themselves less vulnerable, and more skilful than average (optimistic bias) (Johnston, Bebbington, Lai, Houghton \& Paton, 1999; Kumagai, Carroll \& Cohn, 2004a). Also, a person who has taken a step to reduce the risk of their house burning (e.g., created defensible space around their home) may be overconfident thus underestimating their vulnerability (a whole suite of strategies may need to be employed to significantly reduce the risk) (Montz, 1993).

In view of the above discussion, the perceived risk of a natural hazard and vulnerability of those at risk to the hazard is distorted primarily by ignorance and non-comprehension of the hazard. However, people are not entirely unaware of the risks and often do have a good understanding of the risk as well as their own vulnerability but chose to accept or tolerate it. According to Handmer and Penning-Roswell (1990) (in Gilbert, 2004), the perceived probability of a natural hazard is not only distorted by ignorance and noncomprehension, but by recognisable and tangible benefits of the non-hazard experience, and by the existence of family and friends nearby (i.e., awareness

of a sense of community). Ultimately, people balance the perceived risk and the benefit of living in a particular area: the higher the perceived benefit, the greater the risk tolerance (McCaffrey, 2004). 
Understanding the risk perceptions and vulnerability of communities in hazardous areas is important for a number of reasons. Perception of risk and vulnerability can be extremely subjective, and peri-urban communities in particular may have diverse levels of risk perception, in contrast with other areas, because of a diversity of people living in peri-urban areas. Risk perception has been linked to preparedness; at least in theory, a person who perceives a high risk is more likely to act to reduce exposure than a person who perceives low risk (Beringer, 2000; Odgers \& Rhodes, 2002; AndersonBerry, 2003; McCaffrey, 2004). Furthermore, level of risk perception has been found to be influenced (to a variable extent) by awareness-raising programs (Rohrmann, 200oab; Anderson-Berry, 2003). Therefore, in understanding the risk perceptions of people in a community and how they may be influenced, and identifying those who are particularly vulnerable, a community-based approach can be incorporated, which increases the adaptability of community safety policies, strategies and programs addressing risk issues to the uniqueness of the situation as required. Additionally, because people will accept or tolerate risk to a certain degree, an understanding of risk perceptions of the community at hand and the factors which distort perceptions can determine an acceptable level of risk on which policies, strategies and programs may be based.

As would be expected from the discussion of communities and risk perception thus far, a variation in levels of inter- and intra-community risk perception would not be surprising. Research into peri-urban resident's perception of bushfire risk has indeed revealed that there are considerable variations. For example, Monroe and Nelson (2004) found that a large majority (84\%) of sampled homeowners in Minnesota and Florida were very aware of their risk of wildfire, McGee and Russell (2003) reported that almost all respondents (90\%) in a Victorian community adequately perceived the risk of bushfire, and Beringer (2000) compared two communities in Victoria and found that about half (52\%) of the residents in one community and less than half $(36 \%)$ in the other were aware of the high bushfire risk in their area.

\section{Perception of Risk Levels}

In McGee and Russell's (2003) study, the high level of risk perception of many of the respondents, and a good knowledge of bushfire, can be attributed to past bushfire experience and a close association with the local fire brigade. Furthermore, the cohesiveness of the community appears to have lead to similar realistic perceptions of risk of other community members who do not have the same direct experience with fire and have not been as involved with the fire brigade. Unfortunately this community is more of a 'model' community rather than a community representative of peri- 
urban communities. Not all peri-urban communities are as cohesive, which will be explored further in following sections, or as involved with the local fire brigade. This community has more rural than urban characteristics and is very cohesive. The authors did mention that there was some degree of separation between established farm-families and people living on smaller blocks, particularly newcomers, but high levels of risk perception were being maintained through contact between newcomers and the fire brigade, initiated by the fire brigade. Perhaps this community is more representative of a process where community cohesion and the existing social, human and cultural capital is sufficiently strong to maintain the bushfire risk perception.

Although this was not addressed by McGee and Russell (2003), a number of authors have linked risk perception with level of community cohesion in growing peri-urban areas (Anderson-Berry, 2003). For example, Gilbert (2004) observed "the diminishing importance of community [in a Victorian peri-urban area] with increasing numbers of new arrivals to the area" (p. 40), and found spatial differences in risk perception that were tied to community cohesion: people living in the more established and community oriented streets were far more aware of the bushfire risk than people in newer areas.

Beringer (2000) also observed significant differences in bushfire risk perception between newcomers and long-term residents in his study. He explained that new residents cannot identify their level of exposure to risk until they assess the hazards to which they are exposed. He attributed a delayed assessment of the hazard to the reluctance of some people to believe in the reality of a threat, and the interval between moving to the area and receiving bushfire literature from the fire brigade. Information programs have indeed been linked with increased awareness of bushfire risk (Rohrmann, 2000ab; Anderson-Berry, 2003). However results from assessments into the effectiveness of such programs are inconsistent. Providing information on bushfire risk is not a straightforward process and there is not one type of material or method that is consistently successful in raising awareness of risk, and information sources are further subject to a person's biases and preconceptions (McCaffrey, 2004). In any case, newcomers to peri-urban areas appear to become more aware of the bushfire risk over time, and the higher the initial awareness the more aware a person will be with time, leading to a high perception of risk (Gardner, Cortner \& Widaman, 1987). Therefore the initial period of residency of newcomers to peri-urban areas is an important time for developing perceptions of bushfire risk, and low awareness can correspond with the time of the year that the home is purchased (Cortner, Gardner \& Taylor, 1990). In the non-bushfire season, the bushfire risk is not always obvious because of the deceptive appearance of the landscape, and bushfire would not be a current issue 
leading to a possible lack of education and social information indicating the bushfire risk. Additionally, the acceptance of risk depends on the degree of confidence placed in the organisation charged with its management (Smith, 2001 in Gilbert, 2004). For example, distrust in a government may mean that any information received through that government is disregarded thus having no impact on risk perception. There appears to be a greater trust in community-based organisations, such as the local fire brigade and their community schemes, than governmental organisations (Gilbert, 2004).

Gardner et al. (1987) investigated newcomers' perception of risk over time and found that $6 \%$ of respondents surveyed in two Californian communities perceived the fire situation to be very serious at the time they bought their house. At the time of the survey the proportion of homeowners perceiving a serious risk had increased to $27 \%$. These results may reflect newcomers growing connection with the existing community and an increased share in the communities' social, human and cultural capital over time or the exposure of respondents to fire information and brigade personal, for example. Gardner et al. (1987) mentioned that increased awareness of bushfires in their particular study was due to respondents witnessing recent bushfires in the area or obtaining information on these bushfires from media coverage. Many studies have reported that respondents with past personal experience of bushfire have a significantly higher awareness of the risk of bushfire than those with no experience (Blanchard \& Ryan, 2004; McGee \& Russell, 2003; Gilbert, 2004). Winter \& Fried (2000) stated that direct and indirect (e.g., via accounts from neighbours, friends and mass media) experiences with wildfire are more influential in perception formation and reinforcement than the hazard information received by homeowners in their study.

Gardner et al. (1987) also compared risk awareness and perception of risk of people in a fire-affected community and in a non-affected community. They interestingly found that risk awareness in the community that was affected by the bushfire tended to remain low, the non-affected community felt more aware of the danger of bushfire in their neighbourhood. Furthermore, respondents from the affected community assigned a much lower probability of future fire than the non-affected community. The authors suggested that there was a dampening effect on awareness levels and risk perception in the fire-affected community. The respondents may have based their assessment on the adage that lighting does not strike twice in the same place, or on the assumption that the recent fire has reduced the vulnerability of the landscape to another fire. Jacobson, Monroe and Marynowski (2001) also suggested that experience with bushfire reduces the perception of risk, but the type of experience had different effects. The authors found that experience with bushfire smoke was correlated with increased awareness and 
interest in learning more about fire management, perhaps because it reminded individuals about fire without generating great fear. McCaffrey (2004) also agreed that indirect experiences with wildfire are more influential than direct experiences on risk awareness and perceptions. However, she commented that perceptions based on a single experience are limited and biased, but on the other hand repeated experiences can lead to a "disaster subculture" where people become used to the hazard and do not perceive it to be a great risk. Experience with a natural hazard and its effect on risk perceptions therefore appears to be rather inconsistent.

Without reinforcement of risk perceptions such as the reoccurrence of fire or reception of bushfire information, risk perception may change over time. Cunningham and Kelly (n.d.) investigated bushfire perception levels and changes in knowledge over time. They surveyed households in 1993 and 2001 in a New South Wales peri-urban community that was affected by fire in 1985. In 1993, all (100\%) households that had experienced fire understood the high fire risk in their area, in 2001 only $58 \%$ understood the fire risk suggesting a clear attrition in individual perception of risk. Similarly, knowledge about bushfire history decreased between surveys. As time progresses from the fire incident and people recover from the impact and return to their normal lives, the memory tends to fade and other issues begin to take priority. In the same study, the community (including those who had and had not experienced the fire) in 1993 had a good understanding (70\%) of the high fire risk in their street with $33 \%$ of households having experienced the fire. In 2001 only $27 \%$ understood the fire risk despite $26 \%$ of households having experienced the fire. With a similar reduction in community knowledge of bushfire history, this study also highlights a clear attrition in community perception of risk and knowledge. This appears to be subject to individuals changing perceptions over time and possibly a decrease in the instances in which people discuss bushfire issues, it may also be due to changing community structure and processes typical of growing peri-urban areas (i.e., changing community cohesion and social, human and cultural capital), all leading to a lack of collective memory. However, Cunningham and Kelly (n.d.) did not investigate reasons behind the observed changing perceptions of risk of their respondents.

\section{Regulations and Risk}

A few authors have also considered the influence of building codes and regulations on risk perceptions. Institutional arrangements influence how people think about and respond to risk (Winter \& Fried, 2000). Gilbert (2004) found varying effects: those who had built their homes and had to adhere to building codes specifically addressing bushfire safety were more aware of the risk because their attention was thus drawn to the issue; 
however there was no such effect in the new housing estates, because people moving to these areas were largely urban people with little prior knowledge and awareness of bushfire risk, a lack of concern and even interest. However, Montz (1993) suggested that such building requirements may provide a false sense of security to residents, who may see their home as hazard-proof when it is not, thus distorting their perception of risk. Blanchard and Ryan's (2004) study indicated that people who are less aware of the bushfire risk are particularly susceptible to low levels of risk perception after undertaking some degree of fire-proofing. Fire insurance, which is commonly perceived as highly effective in protecting investment from bushfire, as suggested by Nelson, Monroe, Fingerman Johnson and Bowers' (2004) study, may also provide a false sense of security: if it is believed that belongings will be replaced if lost or damaged, perception of risk will be lower (AndersonBerry, 2003).

Anderson-Berry (2003) suggested that "an accurate understanding of insurance status and extent of coverage is essential for an accurate and realistic perception of risk" (p. 226). Although, many people simply consider themselves less vulnerable to hazards than others in the same area who are exposed to the same level of risk. The literature indicates that people in high fire risk areas more accurately perceive the risk of fire in and around the area they live than the risk of fire to their own property. For example, Holden, Jones and Gabler (2000) found that while $64 \%$ of respondents, from a number of Gold Coast suburbs at medium to high levels of bushfire risk, perceived a medium to high fire risk for their area, only $35 \%$ perceived a medium to high risk of damage to their home from a bushfire. This may be driven by an unrealistic perception of preparedness. For example, Holden, Jones and Gabler (2000) also identified a large gap between stated preparedness and actual preparedness. Such gaps between perceptions and actual susceptibility moderates the perceived level of risk, which consequently leads a person to be more at risk.

Many people move to and live in peri-urban areas for non-hazards benefits. The literature clearly indicates that people highly value the aesthetic appeal of the rural surroundings, and that this is the primary reason for living in the area (Gilbert, 2004; Monroe, Bowers \& Hermansen, 2003a). Living in the area because of the importance of community such as to be close to family and friends, as proposed by Handmer and Penning-Roswell (1990) (in Gilbert, 2004), appeared to be a minor motivation throughout the literature. For example, Gilbert (2004) found that just $11 \%$ of respondents cited community benefits, which was suggested to be the result of a decreasing sense of community in his study areas. Nevertheless, such non-hazard benefits do distort perceptions of risk, many people are aware of the bushfire risk but choose to live with it in order to gain the perceived benefits. Most of 
Gilbert's respondents agreed that the benefits of living in their peri-urban area outweighed the risks. Holden et al. (2000) found that people in their focus groups were particularly well aware and knowledgeable about bushfire in their area, but were still willing to take that risk.

Bushfire risk perception has also been related to various demographic and socioeconomic factors. For example Beringer (2000) found that the perceived fire hazard rating decreased with increasing age, he explained that older residents may consider themselves less vulnerable because of increased experience and knowledge of the fire hazards. Gilbert (2004) also observed a pattern similar to Beringer (2000) in one community, however he found the reverse in the other community and suggested that increased experience and knowledge may have alternatively lead to increasing risk perceptions with increasing age. Gender has also been investigated, for example Beringer (2000) and Gilbert (2004) found differences in bushfire knowledge between genders. Men tended to have a better understanding of bushfire, and this was statistically significant in Beringer's (2000) study, and he suggested that a lack of knowledge may lead to females perceiving the bushfire to be a greater threat. Anderson-Berry (2003) linked level of education with risk perception; people with a higher education are likely to have a more accurate perception of risk because they more readily understand the scientific complexities of hazards, and they are likely to be better skilled at searching for and acquiring information. Fothergill and Peek (2004) reviewed the literature concerning the affect of socioeconomic status on risk perceptions; it appears that people of lower socioeconomic status may perceive higher levels of risk possibly because poorer people have little control over their lives and hold little power in the world. However occupation may affect risk perception, people of lower socioeconomic status tend to work in more hazardous occupations which can moderate risk perceptions (Fothergill \& Peek, 2004). Fisek, Yeniceri, Muderrisoglu and Ozkarar (2002) alternatively suggested that socioeconomic status does not affect risk perception; for example income had no effect on overall risk perception. These studies strongly suggest that while demographics and socioeconomic factors can influence risk perceptions, the resultant effect is largely unpredictable.

\section{Expectation of the impact of a bushfire event}

Most people are well aware of the potential major impacts of bushfire, the effects are often experienced through mass media coverage, and many periurban people understand that they live in a fire-prone area. However it appears that there is an overwhelming majority of people who do not expect a bushfire event to occur where they live, or at least whilst they are living there. Considering the high fire risk in most peri-urban areas, most people participating in various studies spoke about "if" a fire comes rather than 
"when" (Monroe \& Nelson, 2004; Nelson, Monroe \& Fingerman Johnson, 2004). People tend to consign rare events to the distant future and do not consider that "some time" could be tomorrow (Kerry, Kelk, Etkin, Burton, \& Kalhok, 1999). If a fire did come however, there were various expectations of the event, and expectations were often based on the perception of bushfire as an uncontrollable or controllable event. Those people who perceive fire as uncontrollable thus expect random and significant destruction where suppression efforts are futile. These expectations were voiced during focus group discussions in Winter and Fried's (2000) study. Participants characterised wildfire as an awesome, uncontrollable force where destruction is inevitable. The participants however, had experienced wildfire either directly or indirectly, and many saw dramatic examples of fire behaviour, examples that contradicted expectations such as houses with a 300-ft-wide defensible space destroyed and wood sheds left standing despite being directly exposed to the flames. It is apparent that these participants did not have an understanding of the impact of embers on buildings. Participants who had directly experienced the fire held stronger beliefs that destruction was inevitable. The authors suggested that such an attitude helps them cope with the issue of personal responsibility for their loss. In the absence of hazard experience, similar expectations of random or total destruction can also be formed by vicarious experiences through the mass media, which tends to focus on destruction and loss of life (Paton, 2003). There are also many misconceptions about bushfire in circulation, which could also lead a person to believe that bushfire is an uncontrollable event. For example, there is the expectation that bushfires are so severe that only houses built especially to withstand bushfire will survive, or that houses explode in bushfires (Ramsay \& Rudolph, 2003).

In contrast, there are people who perceive bushfire as a controllable event and thus expect controlled and insignificant damage, and particularly do not expect their homes or property to be damaged, wholly or even partially. Such expectations may be based on a lack of knowledge, misinformation, or due to beliefs or experience based on successful fire suppression and controlled damage in the past (Kumagai et al., 2004a). It is also likely that these people are most at risk in a bushfire due to a probable lack of preparedness, and late evacuation in the instance where bushfire threatens their home. There were a number of people in Brennan's (1998) study who did not expect that the fire would come near their property, but if the fire did happen to approach, and they felt threatened, they presumed that they would be able to evacuate safely. One respondent said they would "make a spilt-second decision on whether to stay or go and consult with my neighbour [when the fire reached the house next door]" (Brennan, 1998, p. 16), which would have been a very dangerous survival strategy had the fire reached next door. Discussions with respondents indicated that they did not consider what conditions would be 
like when evacuating as the fire approached. Furthermore, residents were more ready to accept that the fire was under control than the fire fighters who were concerned about a wind change. Similarly, during the Ash Wednesday fires there were many people watching the fire front, not expecting to find themselves in the path of the fire and thus not taking any precautions, until the wind changed (Lazarus \& Elley, 1984; Krusel \& Petris, 1992). A lack of knowledge of fire behaviour and conditions, leading to such unfounded expectations, is life threatening. A large proportion of deaths during the Ash Wednesday fires were due to late evacuations, and deliberately entering the fire area, because people did not recognise the real threat to their safety (Krusel \& Petris, 1992). The extreme wind change that occurred on Ash Wednesday, which was unexpected by the majority of people, was associated with most deaths. A respondent in Holden et al.'s (2000) study expressed concern about the general lack of understanding "If there is a fire down the bottom, you've only got 3 minutes. They have absolutely no idea" (p. 3). Additionally, the loss of electricity and water during a bushfire event is in many cases unexpected. Water is obviously a crucial element in fighting fires, and there is a heavy reliance on mains water supply and electricity for water pumps, however these services do often fail because of bushfire. There were a number of examples during the Ash Wednesday bushfires where the fire could have been controlled, and houses saved, if there was water (Lazarus \& Elley, 1984).

The expectation that fire can be controlled on the other hand, may be based on a good understanding of bushfire and mitigative measures. In this instance, expectations of the bushfire event and potential impacts are more realistic. For example, respondents in Nelson, Monroe, Fingerman Johnson and Bowers (2004) and Monroe and Nelson's (2004) studies, who seemed to have a good understanding of bushfire, did not believe that bushfire events were out of their hands, they "had a healthy respect for the damage that a wildfire can do" (Nelson et al., 2004, p. 423). While there was the general expectation that houses prepared for bushfire would withstand the event, they understood that houses and property could be lost, including houses that were prepared, if certain climatic conditions existed.

The Colorado Office of Community Services (Burns, Porter-Norton, Mosher \& Richard, 2003) undertook focus group discussions consisting of 275 people from 29 Western Colorado communities. While it was noted that the participants were not necessarily representative residents of their communities, they were chosen for their good understanding of their respective communities and because they had some awareness of, and interest in bushfire. The participants also had a very good understanding of the direct and indirect impacts of bushfire. Although discussions centred on participants' ideas and concerns about bushfire issues (i.e., did not 
necessarily reflect what the respondents actually expected would happen to themselves or their community), respondents acknowledged that wildfire would impact on the cultural, social and economic fabric of a community. They mentioned the cumulative effects and the negative consequences for the economic health of the region, quality of life and scenic beauty of the area, for example, and the social costs such as neighbourhood relations and other values that cannot be easily reconstructed. This study indicates that there are a considerable number of people who do have realistic expectations, or at least ideas, of bushfire and associated potential impacts. However, through various accounts given by people after experiencing a bushfire, it appears that regardless of a person's understanding, knowledge and expectations of a bushfire event, when a bushfire actually occurs, for many people, the bushfire was not only unexpected but many events that unfolded were unexpected, and pre-conceived expectations were often not met.

Indirect costs, particularly social costs, are difficult to measure, and are often omitted in official loss statistics complied in the aftermath of a natural disaster, and thus do not reflect the true costs of a disaster (David, Baish \& Hearn Morrow, 1999). Therefore, unless one has experienced a disaster, it is difficult to actually know what to expect, and given that people generally do not expect a bushfire to occur, they perceive a low risk of damage to their homes (Holden et al., 2000) and are over-confident in their ability to cope in the event of a bushfire (Odgers \& Rhodes, 2002), it is not surprising that they are shocked when a bushfire does occur. For example, from Halvorson's (2002) investigation into the 2000 Bitter Root Valley (Montana) fires, people described finding themselves "living in harms way", some respondents expressed disbelief or even denial that bushfires were burning close enough to threaten communities. Everyone in the area felt affected, and many were significantly traumatised by the event and experienced multiple anxieties. Various comments from respondents indicate that the magnitude of the event was completely unexpected as were the short and long term psychological, economic and environmental effects. People often do not expect that their basic needs can be compromised (Debelle, 1993), and that it takes such a long time to get back to normal. The 2003 fires in Canberra particularly highlight the latter point, The Age newspaper (Rising from the ashes, 2004) interviewed residents who were affected by bushfire one year after the event, and revealed that very few had rebuilt their homes. This was partly due to planning delays, under insurance and a shortage of builders, but also because of the enormity of the situation, not only rebuilding a home but also lives, which has been overwhelming for some people and impossible for others. 


\section{Expectation of themselves}

What people expect of themselves before, during and after a natural hazard, such as in preparation, protecting property and recovering from disaster, is related to perceptions of who is responsible. Responsibility can be linked with property rights to the hazard. For example, if the risk is regarded as public (i.e., the magnitude of risk an individual faces depends on the actions of others), then the individual perceives him or herself as having little responsibility in reducing the risk and/or dealing with the consequences, if the risk is regarded as private (i.e., an individual's own behaviour determines the magnitude of risk), then the individual perceives him or herself as having primary responsibility. Bushfire risk can be viewed as having both public and private components because various people (e.g., residents and public land managers) contribute to the risk and share, to varying degrees, in the consequences. Perceived responsibility, in particular will play a role in determining which risks are ultimately reduced, and by whom (Winter \& Fried, 2000).

\section{Preparedness and mitigation}

Recent studies investigating bushfire preparedness and mitigation have indeed found that people do perceive some level of personal responsibility. For example, Winter and Fried (1997, cited in Winter \& Fried, 2000, pp. 3637 ) found that most respondents $(80 \%)$ in their Michigan study considered wildfire protection to be either an equally shared responsibility between homeowners and the government (54\%) or primarily a responsibility of the homeowner (26\%). Very few (6\%) saw the government as solely responsible for protection. Furthermore, in accepting some responsibility, most homeowners in Michigan were willing to pay for wildfire protection: willing to pay for protection activities undertaken by the state and/or by the individual (Fried, Winter \& Gilless, 1999); and willing to pay US\$57 per year for a $50 \%$ reduction in risk (Winter \& Fried, 2001). Winter and Fried (2000) investigated which fire protection activities Michigan homeowners viewed as their own responsibility, and found that responsibilities were generally limited to being careful with fire and protecting their own property from wildfire damage, as well as maintaining insurance coverage on their home and personal property. However, because many respondents held the view that fire is an uncontrollable force that burns indiscriminately across ownerships, some declared that fire protection is simply everyone's responsibility. Common fire protection activities cited throughout the literature that people expect themselves to undertake, or are at least aware of, include clearing and removing vegetation around the house (e.g., tree limbs, understorey, grass, leaves), keeping appropriate equipment on hand (e.g., water pumps, hoses, sprinklers), mowing the property, removing 
flammable rubbish, insuring the house and using fire retardant building materials (Monroe, Jacobson \& Marynowski, 1999; Holden et al., 2000; Odgers \& Rhodes, 2002; Nelson et al., 2004). Despite the general perception of personal responsibility and the various activities people know and expect themselves to undertake to fulfil their responsibilities, many people do not actually take action to prepare themselves or their property for bushfire. Taking action can be moderated by several factors. In particular, if a person does not perceive the bushfire risk it is unlikely that they will participate in fire protection activities. In addition, many people who perceive there is a bushfire risk, and even knowing what actions to take to reduce the risk, still do not always undertake fire protection activities (McCaffrey, 2004). For example, a focus group participant in Holden et al.'s (2000) study commented on the distance between awareness and action succinctly; "People are aware of quite a lot of things these days, but few things are put into action. Like my neighbour who is a fire fighter. His property is full of scrub and fallen palm leaves, but he hasn't done anything about it. If anyone is aware, he is; but he hasn't done anything about it" (Holden et al., 2000, p. 4).

According to McCaffrey (2004), in considering mitigation measures, people engage in two types of evaluation: cost-benefit and implementation feasibility. Cost-benefit analysis involves weighing the financial costs against the expected return of the investment over a relevant time frame. Many fire protection measures are costly (e.g., building modifications and removal of large trees), and there is significant uncertainty in estimating the benefit because there is no guarantee of protection from bushfire. "People do not exert any effort "for nothing"; they need to feel that their efforts will pay off" (Kumagai et al., 2004a, p. 30). It is also difficult for people to continually exert resources and effort for long periods of time (Kumagai et al., 2004a). This is particularly true for people on low income (or perhaps restrained by other socioeconomic factors) where costs are proportionately greater than for those on a high income. Turner, Nigg and Paz (1986, cited in Fothergill \& Peek, 2004, p. 92) found that disaster preparedness increases steadily with income levels. Fisek, Yeniceri, Muderrisoglu and Ozkarar (2002) also found that income was an important predictor of behavioural as well as psychological preparedness. A person who does not own their home is also likely to assume higher costs than expected returns because of the shorter time frame typical of renters. Making a relatively large investment for a probable short period of time, and for someone else's property, can certainly be perceived as doing something for nothing. Indeed Beringer (2000) found that non-property owners were less likely than property owners to make even small investments in fire protection, such as cleaning guttering, reading bushfire literature and discussing what their family should do in the event of a fire. Furthermore, people who perceive bushfire as an uncontrollable force 
will be less likely to invest in protection measures because of the expectation that their efforts will be futile (Winter \& Fried, 2000; Nelson et al., 2004)

The feasibility of implementing an intervention includes consideration of the environmental and technical viability of a fire protection activity: how well it fits with the area and current land use, and the availability of skills and resources. It also includes socio-cultural and personal considerations such as whether the activity conforms to personal beliefs, community, mores and laws (McCaffrey, 2004). A significant problem in protecting houses against bushfire is its perceived incompatibility with values about landscape forms, and other beliefs and values about the natural environment. Environmental values are fundamental to "our human identity and fulfilment depend(s) to a great extent on the satisfactory expression of these values... reflect(ing) a profound human craving for affiliating with nature and wildlife" (Kellert, 1996, cited in Nelson et al., 2004, p. 414), or as simply stated by a respondent in Winter, Vogt and Fried's (2002) study; "We live in the woods... because we want to live in the woods" (p. 19). Removing or modifying vegetation around the house is generally seen as sacrificing the closeness to nature, the scenic beauty of the property, privacy, and the conservation of energy afforded through shade trees (Monroe, Long \& Marynowski, 2003b; Nelson et al., 2004; Nelson, Monroe \& Fingerman Johnson, 2005). A resident said that it would affect her emotionally to cut down trees (Nelson et al., 2005), and some felt so strongly about maintaining naturalness that they believed that if a fire did come it should take their house as well as the trees (Nelson et al., 2004), indicating that some people simply value the forest more than their house. On the other hand, in line with different people's values (and also the ecosystem in which they live), whilst valuing nature, some residents also value a well maintained yard with a lawn for example. Therefore in this instance, while not always intentional, people are creating a defensible space to match their particular landscape values (Nelson et al., 2005); "The landscape of any farm is the owner's portrait of himself" (Leopold, 1939, cited in Nelson et al., 2005, p. 323). Although there is evidence that activities and modifications undertaken on one's property need to be "within reason", as determined by the social norm of the community. Respondents in Monroe and Nelson's (2004) study reported social norms about fire preparedness in their communities, however the degree varied from certainty that their neighbours would disapprove of defensible space to equal certainty that their neighbours would not care what they did on their land. The Institute of Medicine (2002) considers such social norms as one of the significant factors in predicting willingness to adopt appropriate safety measures.

McCaffrey (2004) also explained that the lack of action in undertaking bushfire protection activities is additionally due to the fact that people live 
busy and complicated lives, which often means that natural hazards have low salience compared to other concerns. People's judgements about preparation include reasoning about their permanence and their ease of adoption, thus fire protection measures that require little investment in time and effort both initially and over time, are favoured. Through investigating which preparation activities people have and have not undertaken, Odgers and Rhodes (2002) found that the activities actually undertaken were most likely to have been done for reasons other than bushfire, such as cutting back and removing vegetation from around the house and mowing the lawn, which also fulfils the desire for a tidy yard. Similarly, sprinklers and hoses are also installed for the purpose of watering gardens. Odgers and Rhodes (2002) also identified that activities least commonly adopted are those that are deliberate and specific to bushfire risk such as having a non-electric pump and a written plan. This pattern is mirrored throughout the literature and indicates that people in fire-prone areas are generally under-prepared. Furthermore, people who have experienced fire and even indicate their intentions to prepare themselves for a future event do not necessarily take action. For example, Hamer (2001) discussed his neighbour's experience with bushfire which burned the (unmanaged) forest on his property and would have spread to houses along the street if not for a neighbour who stayed behind to fight the fire. After the fire the person cleared the grass under his trees and trimmed the limbs, however in time, with the fire no longer front-page news and new activities and issues needing attention, weeds were neglected and the forest was returning to its pre-fire hazardous state. Hamer (2001) on the other hand, who actually lost his house in the fire, is moving to another peri-urban area, building a fire-proof home, and defying community norms by creating defensible space. Although, experience with bushfire inconsistently influences individual preparedness in the same manner that it influences risk perception, there are a number of examples where people who have lost their homes to bushfire, rebuild fireproof homes (Gilbert, 2004; Thistleton, 2004).

\section{Response and recovery}

The literature clearly indicates that in the event of a fire, a person's first priority is to protect themselves and their family, and, where possible, to protect their property. Families with young children and other dependent persons tend to evacuate, younger people ( $<40$ years) are also more likely to evacuate because of young children and little bushfire experience (Beringer, 2000). However there is a large proportion of people who intend to stay with their house, most of whom are male [67\% in Beringer's (2000) study and $62 \%$ in Odgers and Rhodes' (2002) study] because women tend to evacuate with dependents, and because women may perceive a higher risk due to a lack of knowledge (Beringer, 2000). Those people who intend to stay with 
their homes, expect that they will be able to do so and thus not be forced to evacuate or be stopped by roadblocks on their way home. There are a number of accounts where people have defied the authorities, risking arrest, to get to their homes (Lazarus \& Elley, 1984). People who were prevented from staying with their homes later expressed much anger from the distress that it caused (Beringer, 2000; Odgers \& Rhodes, 2002). Although remaining with the house in a bushfire event significantly increases house survival, and thus will protect people providing they remain inside the house as the fire front passes (Krusel \& Petris, 1992), people with unrealistic expectations of the event and themselves, will be at risk.

Thus, there are many people living in high fire risk areas who do not perceive the risk, do not adequately understand bushfire and the impacts and underinvest in fire protection measures. Despite this, there is a general expectation that they will be able to cope when faced with the danger of bushfire (Odgers, 2002). However when a bushfire event actually occurs many of these people come to realise that they expected too much of themselves. In Brennan's (1998) study, of 43 people or households who had planned to stay with their house during a fire event, only 15 were fully committed (being prepared and confident). The uncommitted households were those who were likely to leave the house at some stage during the fire, despite the intention of staying, which is a dangerous survival strategy. It seems that those who were uncommitted suffered stress from the experience of being alone waiting for the fire, were not confident even when fairly well prepared, or understood that they were not prepared and relied heavily on the fire fighting services. One person's experience during the Ash Wednesday fires describes the physical and psychological stress a bushfire can have on a person; "[we] worked like mad for a couple of hours [preparing the house]... spent half an hour in the pool setting up the reserve pipe to the filter, but I forgot that the electricity was off. I wasn't thinking clearly" (Lazarus \& Elley, 1984, p. 12). To the inexperienced person, it is not always obvious that being prepared for a bushfire involves much more than physical preparations: a person must be fully aware of and perceive the risk of bushfire; understand how bushfires behave; how people and houses survive in bushfires and what to expect during a bushfire; they need to have a comprehensive household plan consisting of what each household member's role will be; and be psychologically ready (Odgers \& Rhodes, 2002). The latter points it seems are most commonly neglected, which leads people to evacuate at the last minute and risk their lives.

People also tend to be overconfident in their ability to recover from bushfire (Odgers, 2002), but various reports investigating people after they have been affected by fire indicate that recovery for many people is not an easy process; it is a stressful and long process. The Sydney Morning Herald (Marriner \& 
Holder, 2004) reported that it took six months for a woman to face returning to the site of her old home and one year after the Canberra fires, which had burnt her home, she finally felt that she was ready to move on. Similarly, a man spoke to Peter Harris (2004) about the year in limbo after the Canberra fires burnt his home, and his struggle to move away from the "bushfire victim" mentality. He wanted everything to return to normal, and in the beginning he thought that it would be possible; they were insured, and possessions could be replaced, and he had his family. However, he and his wife came to realise that they could not return to their prior life, they had lost more than a home, they had lost part of themselves. Furthermore, another couple who also lost their home to the Canberra fires described the struggle with an avalanche of unexpected and unwanted decisions concerning their house and their lives (Campbell, 2003). Even those people who had not lost their homes experienced a traumatic year after the Canberra fires: "The fires have had a big impact on the people who stayed behind... We're living in a very desolate environment, the ambience of the area has gone" (Rising from the ashes, 2004, p. 1). and "The wind blows and it's louder than it ever was before... You don't hear the kids anymore" (Rising from the ashes, 2004, p. 1). There are some instances, however seemingly very few, where the situation has not been so dire. For example, a couple who moved into temporary accommodation (a townhouse) after losing their home to the Canberra fires found that they loved the new lifestyle and living with less, and being free from clutter (Rising from the ashes, 2004).

People who have a strong sense of community or societal commitment, and are generally well prepared and/or in a better position than others for example, feel compelled and that it is their responsibility to lend their support to others during and after a bushfire event. For example, Lazarus and Elley (1984) identified people who, after preparing their own house, helped others to prepare, and people who had equipment to fight the fires protecting their own house as well as neighbours'. One respondent explained that she would not have known what to do if her neighbour had not come and helped her. People in the Bitter Root Valley fires used existing formal and informal social networks and organisations to rally together to help others prepare their houses, and after the fires, to help people affected by the fire to recover; and to "do the right thing". Some people were frustrated when they were not able to do anything to help (Halvorson, 2002). Furthermore, many people, particularly young people, want to be directly involved in fighting fires with the fire brigade; $66 \%$ of the 18 to 25 year old respondents were involved in fire fighting in Beringer's (2000) study, and according to Beringer this perhaps reflects the number of young people who are involved in the local fire brigades. 


\section{Expectation of neighbours and community}

There are some important community characteristics that can determine the resilience of a community, and the individuals living within it, to natural disasters. Buckle, Marsh and Smale (2000) listed a number of factors that support individuals, families and communities to minimise the consequences of disasters including: shared community values; aspirations and goals; established social infrastructure; positive social and economic trends; sustainability of social and economic life; partnerships (between agencies, between community groups and between commercial enterprises); communities of interest (where a geographically diverse group shares a common interest, skill or expertise); established networks; and resources and skills. Similarly, Jakes et al. (2002) highlighted the importance of social capital, human capital and cultural capital in community preparedness for bushfire, and Anderson-Berry (2003) simply stated that "closer-knit communities tend to be more resilient" (p. 226).

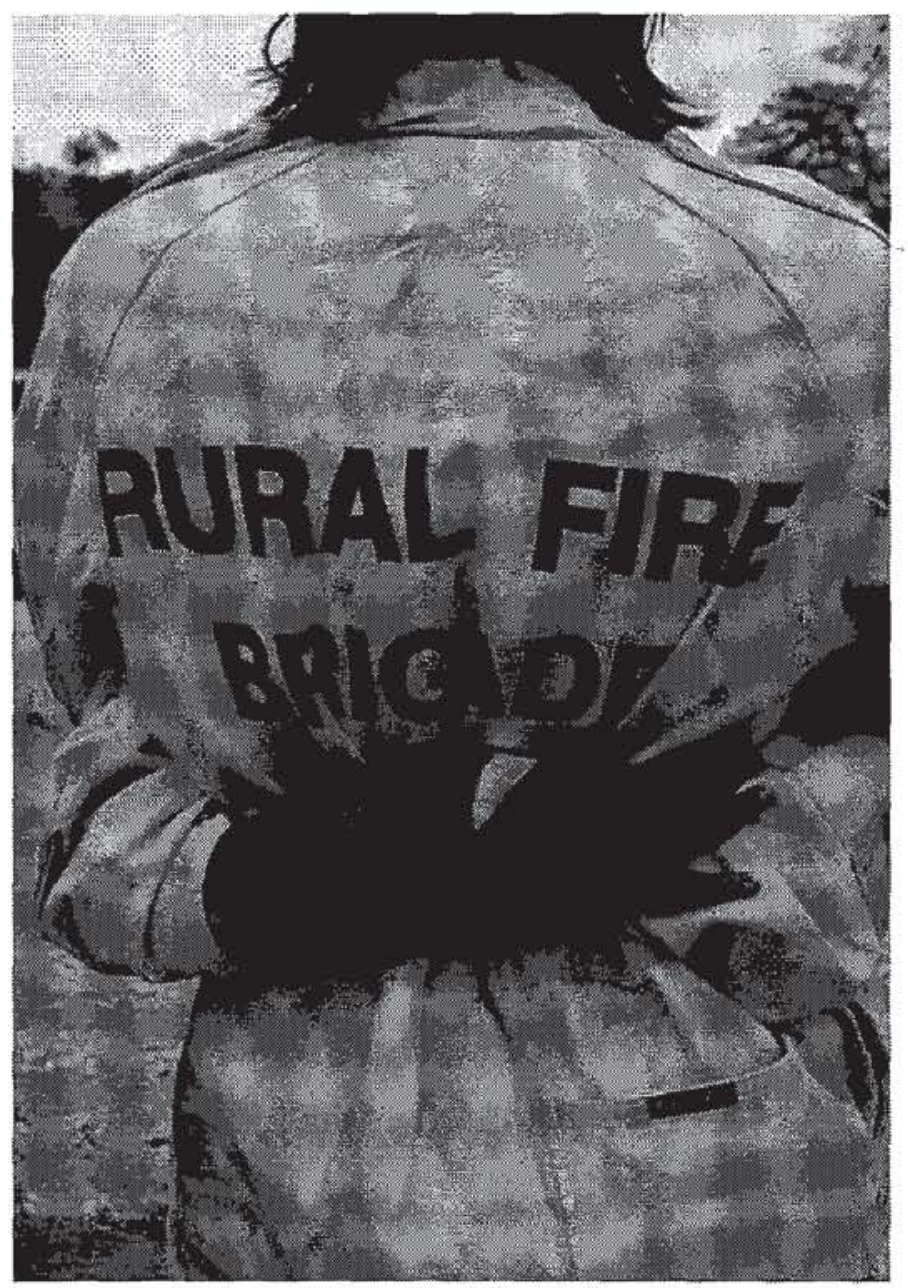

Figure 11.1 Rural Fire Brigade member and cohesiveness 
Being part of a community that is cohesive and rich with the above social characteristics will compel individuals and groups to assist fellow community members in need, as was described in the previous section. It will also mean that community members in need of assistance will look for support from their community. Furthermore, the community will be more likely to act as an organised collective group in preparing for, responding to and recovering from natural disasters. The importance of social responses (e.g., decision making, management and support), together with structural responses (e.g., building materials, defensible space and insurance), to bushfire threats was recently highlighted by Steelman and Kunkel (2004). They noted that social responses will be unique to individual communities: social responses operate at the local community level and consequently take diverse forms in different communities; and the social capacity of a community to respond is strongly dependant on its characteristics leading to vast differences across communities.

\section{Preparedness and mitigation}

A community with the social capacity to respond to a bushfire threat can encourage its individuals and equip them with the necessary skills and resources to undertake measures to protect their home. McGee and Russell (2003) investigated the link between social cohesion and bushfire preparedness and found a positive relationship; there were extensive social networks within the long-term resident community that addressed bushfire preparedness, newcomers however were generally not part of this network and were found to be less prepared for the event of a fire. There is also evidence that individuals in this community are self-sufficient and confident in the face of the bushfire threat because of the strong social network of support. Larsson and Enander (1997) have also suggested that how a person perceives the views of other members of their community to disaster preparations may influence an individual's actions. Although this is an area that needs to be developed more, it is likely that people within a cohesive community that has a positive attitude toward bushfire preparedness, such as in McGee and Russell's (2003) study, will be motivated to undertake fire protection measures because of an expectation of a positive reaction from others. On the other hand, if undertaking fire protection measures is expected to create negative reactions, such as defensible space in a community that values naturalness, it is unlikely that the measures will be undertaken. Hamer (2001) for example, was concerned about the bushfire threat in his neighbourhood and considered creating defensible space around his home, however in a discussion with a neighbour he realised that the action could create considerable negative reaction. He therefore did not create defensible space (perhaps consequently, Hamer's house was later destroyed by bushfire). Flint and Luloff (2005) have explained that a 
community will not take action and mobilise resources, and thus support individual fire protection measures, unless there is a shared community perception of risk. Furthermore, a fire protection measure that requires collective action is also unlikely to be undertaken by an individual unless others in the neighbourhood take action (Paton, 2003). However, in the instance where a community has collectively taken action to reduce the risk of bushfire, there are high expectations that all others in the community will do the same. For example, when "appropriate defensible actions" are not undertaken by residents, this inaction is viewed as personal apathy or irresponsibility (Burns, Porter-Norton, Mosher \& Richard, 2003). In many cases, those who do not join in fire protection activities are newcomers and/or people without a strong connection the community in question, respondents in a number of studies have voiced their concern or frustration with the lack of participation of newcomers in particular (Halvorson, 2002; Gilbert, 2004).

\section{Response and recovery}

Family and community cohesion is an important predictor of an individual's response to a natural hazard; social ties tend to increase the probability of an effective response (Krusel \& Petris, 1992; Anderson-Berry, 2003). Social ties are an important informal communication network. The reception of information during a bushfire is particularly important to enable people to make informed decisions about what actions should be undertaken and when. During the Bitter Root Valley fires, residents responded to the general confusion of whether to evacuate or not by monitoring various conditions to judge the level of risk and then disseminating this information, which was tailored to the needs of others in the community, through various information networks (Halvorson, 2002). Bitter Root Valley is a good example of a community with the social capacity to respond effectively to bushfires, and community members, particularly those born and raised there and thus closely affiliated with the community, rely on this social capacity for support and, as a community, to be independent from outside groups. For example, many evacuated residents did not utilise the Red Cross shelter because they sought accommodation with friends and family, or camped with other families by the river (Halvorson, 2002).

In the bushfire aftermath there was a similar "pulling together" within the Bitter Root Valley community. As discussed previously, community members established formal and informal support networks to help bushfire victims. A strong sense of community emerged both during the bushfire and after, and the experience of dealing with the fire hazard seemed to give an additional sense of identity to the communities (Halvorson, 2002). Kumagai et al. (2004a) explained that "a community's disaster recovery processes reflect 
the community's pre-disaster social and physical conditions" (p. 31). Indeed the Bitter Root Valley communities were well prepared for disaster and were thus able to deal effectively with the aftermath; it appeared that the majority of people in need of assistance and support received assistance and support from fellow community members. Halvorson (2002) did identify victims who were not well established or connected to the local community, and these people fell outside of the community networks, however, critical financial and moral support was provided by external aid, the efforts of which were enhanced by the community support networks. Without such a strong sense of community and informal and formal community support networks, preparedness, response and recovery efforts would have proceeded incrementally and haphazardly (Halvorson, 2002). The existence of active community leadership has also been identified as an important component of hazard mitigation, response and recovery (Petterson, 1999; Reddy, 2000). There is a need, if not an expectation, for somebody, particularly existing community leaders, to activate and organise the community and its resources to respond to hazards effectively. Most research shows that such leadership does indeed emerge in the situation of a hazard (Petterson, 1999; Reddy, 2000). Despite the expectations of fellow community members that a person may have in times of crises, it appears that people are nevertheless amazed and heartened by the level of support that was actually received. Even people from the Bitter Root Valley communities expressed amazement: "The community pulling together was amazing for me" (Halvorson, 2002, p. 7).

Many studies investigating the weeks or months after a disaster have reported the pulling-together of communities, even communities that were not cohesive pre-disaster (Moore, Daniel, Linnan, Campbell, Benedict \& Meier, 2004). Such collective moments are termed "altruistic or therapeutic communities", however this is not a long-term effect. Participants in Moore et al.'s (2004) study described the later phases (after experiencing the therapeutic community) of the Hurricane Floyd flood disaster in North Carolina as being characterised by a general lack of concern on the part of fellow residents (and governmental authorities). As a community begins to recover and the effects of the disaster become less apparent, memories fade, people are less willing to help and other issues and problems begin to take priority. For many, a period of disillusionment and anger entails the experiences and perceptions of high levels of trust, social cohesion, or collective efficacy, possibly leading to changes in the way these people view their community and their place in it (Moore et al., 2004). Hoffman (2000) also described the dichotomy of a community following the Oakland Berkeley Firestorm in 1991. "At first the outside community saw us with sympathy. Eventually, when recovery took longer than the day, week or month they envisioned, they came to view us as greedy whiners and 
undeserving receivers of pots of gold" (p. 6o). Driven by jealousy, the disaster victims thus became targets of wanton envy, they were viewed as "lucky" because they had all new things and would eventually have new houses. In response, disaster victims withdrew from the outside community and adopted equally separating, and in due course dehumanising, conceptualisations to mark them.

A human-caused or "technological" disaster can also set the stage for anger and conflict as victims blame what they perceive to be the responsible party and disagree over remediation measures (Carroll, Cohn, Seesholtz \& Higgins, 2005). Bushfires have elements of both technological and natural disasters. Bushfires are a natural occurrence in many parts of the world, however, they can also be started by a deliberate or accidental human act. Technology also plays a role in suppression and management of bushfire. Carroll, Cohn, Seesholtz and Higgins (2005) investigated bushfire as a galvanising and fragmenting influence in three Arizona communities and found that although the disaster literature is replete with examples of communities suffering internal conflict in the aftermath of disaster events, there was little within-community tension and conflict in the communities studied. Rather, the communities pulled together. However, much of the disaster literature in this area does not address bushfire, therefore further investigation is warranted. Tension and conflict were apparent, but most of the blaming behaviour in these communities was directed at outside agencies, which will be discussed in later sections. Kumagai, Bliss, Daniels and Carroll (2004b) suggested that it should not be assumed that community responses to bushfire events are simple or predictable.

\section{Expectations of Organisations}

The public perceive the primary responsibility of fire and emergency services to be fire suppression and protecting people and property, and, in most cases, the fire services in particular are perceived to fulfil their roles effectively. Holden et al.'s (2000) study suggested that regardless of a person's awareness or knowledge of fire brigades, most people highly value the fire brigade that services their area, even people who are not sure about which type of brigade actually services their area. Furthermore, Gilbert (2004) revealed that there is a general high level of confidence in local brigades. Such positive views may be attributed to a number of factors: fire fighters are often depicted at the front line of a bushfire, risking their lives to save others and are thus often viewed as heroes; and local brigades in particular are usually part of the community with family and friends volunteering and working for the community. As a result local fire brigades are viewed as distinct from government agencies. 


\section{Preparedness and mitigation}

Efforts made by fire brigades and their community schemes such as Community Fireguard (CFA, Victoria), to communicate with the local community appear to be well appreciated. There is an expectation that the information received by the local brigades is accurate and tailored to local conditions, and is thus perceived as credible. Participants in McGee and Russell's (2003) study indicated their preference for information from the local fire brigade, above other information sources. It was also suggested that most people in this community prefer to actively seek such information themselves, however, these people also tended to accept much of the responsibility to respond to the bushfire threat. People in other communities generally do not perceive themselves as having such a high level of responsibility, and are less resourceful, and consequently rely on others to provide information. The opinion that fire brigades adequately liaise with the general public appears closely related to whether residents have had contact with the local fire brigade since living in the area. For example $67 \%$ of residents in Beringer's (2000) study had had contact with the local fire brigade and $67 \%$ felt there was sufficient liaison between the CFA and the general public. Therefore, although people highly regard and prefer information received from their fire brigade, there does not appear to be an expectation that fire brigades will be visibly active and have regular contact with residents to provide information. Holden et al.'s (2000) study revealed that only $5 \%$ of respondents thought that information delivered through door knocks and one-on-one meetings would be effective, the majority indicated that literature in the form of a pamphlet, booklet or leaflet $(65 \%)$ and television (15\%) would be the best delivery mode. Furthermore, in Odgers and Rhodes' (2002) study, respondents believed that fire brigades should assign a higher priority to bushfire hazard reduction than educating the public. Similarly, Holden et al.'s (2000) respondents thought that fire brigades should take a more active role in prevention, however; it was perceived that brigades are constrained by a lack of resources and sometimes authority.

\section{Response and recovery}

During a bushfire event there is a huge reliance on fire brigades and emergency services, as would be expected. However, it is clear throughout the literature that a majority of people expect too much of these services, in particular many people expect that fire fighters will be available to protect their homes and that they will be specifically warned and told when to evacuate (Beringer, 2000; Gilbert, 2004). These expectations are based on a lack of awareness; indeed emergency service priorities are to protect people and property, but in a major fire event these services are often overwhelmed 
and not able to meet such expectations. Furthermore, front line fire fighters do not always have the most accurate and up-to-date information (Brennan, 1998), and, possibly as a result, actions taken by fire and emergency personnel are not always the most appropriate. For example, there are a number of instances where people have been evacuated, from their otherwise safe homes, during the height of the fire (Braun, 2002).

Newcomers and those who have not experienced a bushfire, who are more likely to rely heavily on emergency services, are most often astonished by the fires and the alleged lack of emergency services (Halvorson, 2002). Carroll, Findley, Blatner, Mendez, Daniels and Walter (2000) also mentioned that people's emotional reactions tend to be equal to the fire's magnitude and intensity. One community in their Washington study appeared to be more emotionally charged and more likely to give rise to conflict than the other two communities because a section of this community experienced some serious direct impacts that the other communities did not. Although such astonishment and conflict may lead to blaming behaviour, it is more likely that the government and its agencies, including federal fire services, will be blamed rather than local fire brigades (see next section). After experiencing a bushfire, the community in Odgers and Rhodes' (2002) study praised the fire services despite an overall opinion that they could have been better prepared, the local government was generally viewed as ineffective and criticised for its lack of action.

There is obviously a great reliance on emergency aid organisations after a major bushfire, particularly for those people who do not have strong social connections to the community. However, it would appear that there is also a large perception gap between what fire victims expected and what occurred. Two major themes surfaced from Carroll et al.'s (2005) study: individuals expected both a better organised and more effective distribution of financial resources and a more sympathetic and caring response; and a more equalised distribution of resources between the three communities affected by the bushfires. This resulted in considerable tension between the communities and the American Red Cross to the point that the organisation was picketed by locals. Furthermore, the unequal distribution of resources created considerable conflict between the three communities. Unequal distribution of aid appears to be a common occurrence post-disaster, but is nevertheless unexpected (David et al., 1999; Moore et al., 2004), and people of lower socioeconomic status are often further marginalised (Fothergill \& Peek, 2004). 


\section{Expectation of government}

Because bushfire risk has a considerable public component, and bushfires are commonly perceived as a technological hazard, all levels of government are perceived to be responsible to some extent to mitigate bushfire and its impacts. However, although there is the general expectation that governments need to take action, which actions and to what extent can vary considerably from person to person and area to area. Much of the literature investigating people's reactions to or acceptability of mitigative measures has been based on the Theory of Reasoned Action, which suggests that beliefs are a strong predictor of attitudes and attitudes are a strong predictor of behaviour (Bright, Vaske, Kneeshaw \& Absher, 2002; Vogt, Winter \& Fried, 2002; Vogt, Winter \& Fried, 2005).

\section{Preparedness and mitigation}

People's knowledge and perceptions of fire and fire policies are becoming more sophisticated. Thirty to 40 years ago people generally believed that fire was bad and thus supported aggressive suppression. As people became more knowledgeable about the beneficial effects of fire, attitudes changed and support for suppression-only policies gave way to fire management (Cortner, Gardner \& Taylor, 1990). In most instances, fire management on public land is expected, but opinion on how this should be done varies. Prescribed burning and mechanical fuel reduction, the major fuel reduction techniques, have both been the subject of controversy. For example, in the USA mechanical fuel reduction has been broadly supported but environmentalists are suspicious because fire more closely mimics natural disturbance patterns, and they have accused the federal forest agencies of using fuel reduction as an excuse for logging. The timber industry and many foresters are equally suspicious of prescribed burning, which they consider as wasteful, and dangerous because of the risk of the fire getting out of control. Similarly, grazing as a fuel management technique has attracted debate (Brunson \& Shindler, 2004). Peri-urban resident opinion has also led to controversy over fire management techniques, however, judgements of acceptability can be based on a variety of factors. For example, using a Theory of Reasoned Action approach, Bright, Vaske, Kneeshaw and Absher (2002) identified six basic belief dimensions that may influence a person's perception of bushfire management: anthropocentric; biocentric; responsibility; capable/trust; freedom; and benefit/harm. Knowledge, experience and personal importance are also entwined with acceptability judgements.

A study undertaken by Daniel, Weidemann and Hines (2002) in northern Arizona has suggested that people who value the beauty of forested areas, or 
value nature for what it provides humans (i.e., the anthropocentric belief dimension), are less supportive of fuel management strategies that compromise aesthetic values. Prescribed burning and bare fuel breaks in particular do not protect aesthetic values. However, there was evidence that people in the above study would support other fire management strategies that address the safety-aesthetic value trade-off. Newcomers to peri-urban areas are perceived to be more anthropocentric. Participants in Monroe et al.'s (2003a) study, including various government, non-government and industry representatives as well as homeowners representing 13 southern US states, indicated that newcomers were viewed as not connected to the land and environmentally irresponsible because they planted exotic species and complained about bushfire smoke. On the other hand, people who valued 'naturalness', leaving forested areas as natural as possible (i.e., the biocentric belief dimension), were more supportive of prescribed burning because it reflects a natural ecosystem process (Nelson et al., 2004; Nelson et al., 2005).

The perception of who is responsible for reducing the bushfire risk can influence the acceptability of fire management strategies. As previously discussed, a person who regards the bushfire risk as public will perceive the government as primarily responsible for reducing the risk and will thus expect institutional intervention, consequently leading to institutional legitimacy (Winter \& Fried, 2000). Much of the literature suggests that people are more in favour of fire management policies that require the government to take action rather than themselves (Gardner et al., 1987; Blanchard \& Ryan, 2004). However, with regard to private property, many people do perceive themselves as responsible for protecting their own house. They are not supportive of any policies that require homeowners to take steps to reduce the risk themselves, because such policies would also impinge on perceived rights to freedom. Therefore reducing the fire risk on public land is perceived as government responsibility primarily, and fire management policies that address the risk on public land are supported, if not expected, particularly when homeowners are implementing fire protection measures on their own property. A lack of action on public land nearby can also moderate private landholder mitigation measures (Kent et al., 2003; Anonymous, 2004). However, once again, which specific policies will be supported and by whom, will vary.

Trust has emerged as an important factor influencing public opinion of fire management strategies (Vogt, Winter \& Fried, 2002; Winter, 2002; Vogt, Winter \& Fried, 2005). Trust in the government to implement a fire management strategy is closely related to the perceived competence of the government to implement the strategy successfully. For example, there are a number of instances where prescribed burning became out of control and 
threatened people and properties, therefore the government agency is viewed as incompetent and consequently is not trusted to undertake prescribed burning safely. As a result people have intensely rejected prescribed burning as a fire management strategy (Winter \& Fried, 2000; Vogt et al., 2005).

There is an emphasis on individuality and self-reliance in the western world, and the right to free choice is an important concept (McCaffrey, 2004; Bright et al., 2002). Therefore government actions that restrict or dictate what is done on private property or affect private property values may be resisted. Indeed, homeowners are not supportive of policies that affect the way they manage their property. Participants in Winter and Fried's (2000) study were not supportive of building codes, safety ordinances, zoning and regulations to modify vegetation on their own property. They wanted the opportunity for voluntary compliance and thought that such policies would be unnecessary because of existing and potential insurance markets, and that it would detract from aesthetic and convenience aspects of their homes. Blanchard and Ryan (2004) suggested that local residents may support land-use regulations, including building codes, for new developments because it would not impinge their own property rights. Residents in the Burns et al. (2003) study, who appeared to have a good understanding of the fire risk and the importance of mitigation, were in full support of land-use planning and building codes. New residents may also be supportive because there is still an element of free choice: they can choose to live in a lower fire risk area if they do not agree with such regulations.

A belief that bushfire is harmful to nature may lead a person to not support management strategies such as prescribed burning. However, an increase in knowledge of bushfire and its effects can influence such beliefs. Cortner et al. (1990) discussed the general increase in people's knowledge of the effects of fire over the last four decades and an increasing positive attitude toward fire (e.g., bushfire is beneficial to nature). Loomis, Blair and Gonzalez-Caban (2001) investigated the effect of knowledge on attitudes toward prescribed burning and found that Florida residents' attitudes were more supportive of prescribed burning as knowledge increased. Therefore an increase in knowledge may change a person's perception of bushfire, which may then lead to the acceptance of prescribed burning. Indeed, knowledge has been found to be an important consideration in reactions to fire management issues (Winter, 2002). Blanchard and Ryan (2004) revealed that respondents in their south-eastern Massachusetts study who have a high level of knowledge about a specific fire hazard reduction strategy were more likely to support the use of that strategy. It has therefore been suggested that the public be educated about fire management issues (Winter, 2002; Blanchard \& Ryan, 2004). Loomis, Blair and Gonzalez-Caban's (2001) study suggested that educational information can increase knowledge leading to 
attitudes that support prescribed burning. However, once again, the effectiveness of public education programs in influencing attitudes or knowledge, and behaviour, has been questioned (Cortner et al., 1990). Although, it seems that the public expects to receive educational material, participants in Winter and Fried's (2000) study were overwhelmingly favourable toward educational programs designed to reduce fire ignitions. However this was because of a belief that human action, mainly that of newcomers and visitors who are viewed as ignorant of the fire danger, is the cause of most forest fires. Participants in other studies have indicated their desire for information on other bushfire issues such as bushfire awareness and preparing homes (Gilbert, 2004). Furthermore, there is particular demand for more innovative and community-based information, for example information that details how to protect homes from bushfire whilst maintaining aesthetic values (Creighton, Baumgartner \& Gibbs, 2002), and more specific information that assists people to purchase fire protection products that are appropriate to their needs and budget (Odgers, 2002).

The effect of personal experience with bushfire on attitudes toward fire management strategies is also questionable. Vogt (2002) investigated seasonal and permanent homeowners' past experiences and approval of fuel reduction and found that seasonal homeowners had less experience with bushfire and fuel reduction techniques, however, there was general support from both seasonal and permanent homeowners for prescribed burning and mechanical fuel reduction. Jabobson, Monroe and Marynowski (2001) and Vogt et al. (2005) similarly found no significant effect of past experience with bushfire on attitudes toward fire management. On the other hand Blanchard and Ryan (2004) suggested that past experience with bushfire can increase the level of support for prescribed burning because people who have witnessed fires in the past may have become more comfortable with them. Although it may depend on the type of experience; participants in Winter and Fried's (2000) study who witnessed significant destruction due to an escaped prescribed burn were suspicious of prescribed burning and generally not supportive of it as a fuel reduction strategy. Additionally, because the past experience with bushfire led many to believe that it was an uncontrollable force, investment in suppression infrastructure was considered pointless, although it was acknowledged that the government needs to respond to bushfires that do occur and ensure that fire fighters are well equipped for their own safety.

Vogt et al. (2005) investigated the effect of personal importance (or personal relevance to fuel management techniques) on homeowner's approval of fuel management techniques. They found that personal importance was a good predictor of approval. For example, from the same study, Winter, Vogt and Fried (2002) indicated that if vegetation amenity is important to a person, 
defensible space compliance will likely be disapproved, if property rights are important, any ordinances impinging on such rights will likely be disapproved, and if smoke sensitivity is an issue, prescribed burning will also likely be disapproved. However, Vogt et al. (2005) also highlighted the wide range of factors in addition to personal importance, including belief dimension(s), knowledge and experience discussed above, and also social and environmental factors associated with where a person lives (e.g., demographics, political traditions and ecosystem type), that are intricately linked leading to great variations in opinions and acceptability of fire management practices between and within locations. Brunson and Shindler (2004) found such differences in their western USA study suggesting that government policies addressing bushfire management need to be adaptive to the local situation at hand.

\section{Response and recovery}

With increasing knowledge, people's expectations of how the government should respond to a bushfire are changing (Cortner et al., 1990). For example, people do not necessarily expect a fire to be immediately suppressed, however, this depends on a number of factors. For example, Kneeshaw, Vaske, Bright \& Absher (2004) investigated situational influences of acceptable wildland fire management actions, they found that fire origin was one of the most important factors for "put the fire out" and one of the least important factors for "let the fire burn"; if the fire was ignited through lightning there was support for letting the fire burn, and conversely if the fire was ignited through human carelessness there was support for putting the fire out. Furthermore the relative importance of risk of private property damage and forest recovery was consistently high in influencing acceptability of management actions; if the fire posed a risk to private property and if forest recovery were to take many years there was support for putting the fire out. The relative importance of air quality was minor but there was general support for putting the fire out if air quality became poor. The relative importance of outdoor recreation was lowest, if a recreational area was closed due to the fire, recreating in another area nearby may be an acceptable substitute. Past experience with bushfire is also an important factor, however once again the effect will vary depending on the type of experience.

In the USA, federal fire services have been criticised in their efforts to collaboratively fight fires with local services. Federal fire services focus on the big picture of the fire as a generalised event whereas local services have a more place-specific view. Some people view this as depersonalisation, which grates on local residents and fire fighters whose particular homes and special places are at risk (Carroll et al., 2005). This was the underlying cause of 
much of the post-fire conflict in the communities of Carroll et al.'s (2005) study. It appears that local fire fighters expected that their knowledge, skills and commitment would have been better valued, and utilised. They also felt too constrained by the rules and decisions made at higher levels, and this led to local fire fighters and homeowners defying the instructions of the Incident Command System. Federal services were also accused of putting the majority of their resources into fighting fires in one community, leading to intercommunity conflict. Carroll et al. (2005) explained that "the relative inflexibility of rational, bureaucratic systems was seen as unable to adapt to quickly-changing conditions, something at which the spontaneous creation of local helping systems seemed more adept" (p. 316). This highlights the importance of the government and its policies to become more attuned to local situations, and the importance of communities to become more organised and better prepared to be able to respond to bushfire. This would lead to effective collaborative efforts that significantly increase the resilience of the community.

The government however, is often blamed in the event of a bushfire. Blaming behaviour has been well documented among people affected by disaster, and this phenomenon can create much hostility toward the organisation or institution that was supposed to protect people from disaster (Kumagai et al., 2004a), namely the government and its agencies responsible for some aspect of fire protection. Just $33.8 \%$ of respondents in Odgers and Rhodes' (2002) study felt that the local government was effective in responding to bushfires, compared with $92 \%$ of respondents indicating that the fire service was effective, and although reasons were not given, there appears to be a general public opinion that governments are ineffective in their efforts to mitigate bushfire. Blaming behaviour can be the result of whether property damage was incurred, whether or not a person maintained a sense of control, and/or whether the bushfire was perceived as primarily natural or technological (Kumagai, Bliss, Daniels \& Carroll, 2004b). Participants in Kumagai et al.'s (2004b) study who incurred property damage from the Butte Complex Fires in Nevada in 1999 attributed the damage to "others actions", specifically backfires started by the California Department of Forestry and Fire Protection (CDF) in spite of the fact that there was no public evidence of such backfires. The study also indicated that people who had lost their sense of control tended to attribute damage to factors associated with fire fighters and the CDF. Losing one's sense of control was associated with a belief that their property did not receive adequate attention from fire fighters, and not being able to obtain up-to-date information during the bushfire. Participants who viewed the fires as the result of nature (rather than technology) were less likely to blame others, one respondent acknowledged the build up of fuel as a contributing factor to fire magnitude but said that humans can not do 
anything about events that "are totally the act of God" (Kumagai et al., 2004b, p. 120).

The primary expectation of all levels of governments post-disaster is the provision of assistance, and in many cases actual assistance received falls short of what was expected. Controversy about government assistance after the Canberra bushfires was well documented throughout the media (Government must do more, 2003); \$5000 per rebuilding household was considered miserly and not enough to rebuild social capital and address the social issues following a disaster. Years after Hurricane Floyd in North Carolina, families were still waiting for promised assistance, and for authorised repair and replacement units, which affects the trust that residents have in their local government (Moore et al., 2004). Communities rely on external assistance to mitigate the economic impact associated with natural disaster, and indeed, with such assistance, disaster can result in economically positive impacts on a stricken community (Kumagai et al, 2004a). However, there are a number of issues concerning disaster assistance, primarily the issue of equity. As previously discussed it is not uncommon that assistance, from both government and non-government organisations, does not adequately address those most in need (David et al., 1999; Fothergill \& Peek, 2004). Secondly, because of disaster assistance, the costs of disaster are borne not only by those affected, but also by the community, all levels of government and the general population (Cortner et al., 1990). Thirdly, there is evidence that people may not undertake preventative measures, such as home insurance, in view of the existence of disaster recovery programs (Cortner et al., 1990; McKee et al., 2004). Because people expect that they can live where they wish, continually putting themselves in dangerous situations and thus creating such economic problems, Sowell (2004) has suggested phasing out state and federal disaster relief and relying more heavily on prevention and mitigation activities, particularly insurance. After a disaster there is an expectation of government that actions will be taken to prevent another disaster. For example, after Hurricane Floyd, people were sceptical about whether their counties' had learned anything from the disaster, respondents mentioned that, since the flood, counties had not done a good job of keeping drainage ditches free of debris and that bridges were not high enough to surmount future flood levels (Moore et al., 2004). Disaster prevention, however, such as relocating and redesigning infrastructure, can be influenced by a communities' desire to "return to normalcy" as quickly as possible, which does not create a positive environment for orderly, well-planned reconstruction processes (Petterson, 1999). Similarly, recovery planning can become thwarted by old perceptions and mental pictures of the community as it was before the disaster (Petterson, 1999). Furthermore, in terms of encouraging homeowner participation in preventative measures, policies are not well accepted. 
However, respondents in a number of studies have indicated that they support citizen involvement in developing fire hazard reduction programs (Blanchard \& Ryan, 2004), which is important because such programs and policies need public input to be able to deal with the realities of public expectations as well as the realities of the biophysical environment (Cortner et al., 1990).

\section{Expectation of the media}

\section{Prevention and mitigation}

The media has a significant influence on public knowledge, perceptions and opinions. Many studies have linked respondent knowledge and perceptions of bushfire and opinions of bushfire management with information disseminated by the media. For example, Cortner et al. (1990) reported that the news media, second to experience, was a way in which people were made aware of the bushfire hazard. Jacobson et al. (2001) found that public opinion about the benefits of prescribed fire closely matched the benefits identified by the media, and similarly Loomis et al. (2001) suggested that media coverage of bushfires in Florida contributed to Florida respondents' knowledge and support of prescribed burning. There is also evidence that people prefer bushfire information to be delivered via the media; respondents in Holden et al. (2000) indicated that television, second to literature (e.g., pamphlet, booklet), is the best delivery method for bushfire information. However, Monroe and Nelson's (2004) study has suggested that the media is not always a trusted source, and indeed in the USA for example, there has been cause to distrust the media because of conflicting messages (Cortner et al., 1990; Burns et al., 2003). Respondents in Monroe and Nelson's study (2004) indicated that written news and televised interviews with experts are better trusted. Focus groups discussions in the Burns et al. (2003) study revealed that people believe the media should be more proactive, not only by providing more accurate and objective information but by discussing the complexity of bushfires and the benefits of prescribed burning, and explaining "why" mitigation action should be taken, rather than providing mere informational messages. "The well functioning of a modern society is based on the good and fast circulation of information. This is even more relevant in the case of a society vulnerable to natural hazards" (Anonymous, 1998, p. 21). Information (collection, production and dissemination) and communication media are a crucial link in the chain of sound prevention measures and awareness-raising (Anonymous, 1998). 


\section{Response and recovery}

In a bushfire event people rely heavily on and need information to make effective decisions, and although emergency services remain responsible for the communication of risk (Krusel \& Petris, 1992), the media plays a crucial role. Often the media is the only potential source of information during a fire. From Lazarus and Alley's (1984) study, it appears that many people during the Ash Wednesday fires could not use phones, lived a significant distance from neighbours and/or had no contact with emergency services, however, they did have access to a radio and/or television but there were reports that the media did not provide adequate information. As a likely consequence, some of these people did not know the fire was in their area until it reached their house. There are a number of reports suggesting that the media could have done a better job of warning people of an impending hazard (Moore et al., 2004). Furthermore, Odgers and Rhodes' (2002) study suggested that people would like the media to provide more specific information during a fire event, such as the location, severity and direction of the bushfire.

The media can also influence the recovery cycle of a community after a disaster. For example, the 2002 Rodeo-Chediski fire in northern Arizona highlighted the influence of media coverage during and after the fires on the magnitude of recovery assistance received by a community. One community, of three affected by the fire, received the most media coverage and as a result received the most help offers from ordinary people and helping organisations wanting to contribute money and other resources to aid in recovery. This inequity contributed to the tension and conflict observed in the aftermath (Carroll et al., 2005).

\section{Expectation of insurance agencies}

Insurance agencies are obviously depended on for money to rebuild homes, however, often a person's insurance policy does not cover $100 \%$ of the loss, which is commonly unexpected because people may not realise that they live in a fire-prone area or forget to update their policy, for example. However, there are also unanticipated disputes between fire victims and their insurers. For example, in the aftermath of the Canberra fires a woman claimed that her insurance agency was unreasonable in offering to pay only two-thirds of her home insurance, because it did not cover the concrete slab, which had been compromised according to an engineer, and the assessment excluded part of the house (Morris, 2002). Although it is primarily the responsibility of the person buying insurance, there is a need for insurance agencies to undertake an awareness raising role concerning people's insurance policies, which, if effective, would lessen the financial repercussions. 
Cortner et al. (1990) revealed that people in a fire-affected community who did not update their policies were provided an economic advantage because they were able to apply for a low interest loan, which effectively provided the resources to rebuild bigger and better homes than their neighbours who had updated their policies. There is also perhaps a need for insurance agencies to play a role in promoting homeowner bushfire preparedness, via mechanisms such as a reduction in home insurance premiums if a house is constructed of fire resistant materials, as was suggested by a respondent in Winter and Fried's (2000) study.

\section{Conclusion}

This review of community expectations of bushfires and the impact of bushfires on communities shows quite clearly that there are considerable differences between and within communities in terms of bushfire awareness, perceptions of bushfires, expectations of what happens during a bushfire, the impact on individuals and communities, and expectations of the roles of various organisations. The implications of this are substantive and fraught with difficulties for service delivery and applied social research. Locality clearly remains important and it often falls to the local service providers to understand the expectations and beliefs held by the communities they serve. There is a clear need to identify effective strategies for service providers to understand and engage with their communities. The challenge for applied social researchers is to identify and develop appropriate strategies or models for engagement. 